\begin{abstract}
Resumo
A partir da indagação conceitual própria da psicanálise no campo da educação, este trabalho apresenta elementos para pensarmos o infantil em nossas práticas cotidianas com as crianças e adolescentes. Nesse sentido, questionam-se os discursos cientificos que produzem uma noção universal, atemporal e ideal de infância, na medida em que tal idealizaçãa comporta a recusa do adulto em relação ao seu dever à formação dos mais novos. Destaca-se o estatuto do sujeito do desejo e as possiveis posições que a criança assume junto à demanda do adulto.

Descritores: infância; infantil; educação; psicanálise.
\end{abstract}

\section{DE A-CRIANÇA AO REAL INFANTIL: REFLEXÕES PSICANALÍTICAS ACERCA DA INFÂNCIA}

\section{Eric Ferdinando Kanai Passone}

DOl: http//dx.doi.ors/10.11606/issn. 1981-1624.v21i1p114-132.

Se o infantil sexual descoberto por Sigmund Freud sustenta sua tese da atemporalidade do inconsciente, nada mais pertinente do que interrogarmos o imaginário social contemporâneo acerca da infância. A psicanálise nos mostra que a realidade instituinte da infância é, antes de tudo, uma realidade psíquica delimitada pelo campo do desejo e da palavra, apostando na singularidade e historicidade dos processos de subjetivação. Entende-se, assim, a especificidade da infância no interior mesmo de um sonho moderno de sua própria invenção, isto é, fruto de nossa cultura e, como tal, marca de nossa frágil condição histórica e humana.

- Psicanalista. Pós-doutorando no Laboratório de Estudos e Pesquisas Psicanalíticas e Educacionais sobre a Infância da Faculdade de Educação da Universidade de São Paulo (USP), docente na Faculdade de Psicologia da Universidade Metodista de Piracicaba (UNIMEP) e pesquisador associado do Núcleo de Estudos de Políticas Públicas da Universidade Estadual de Campinas (NEPP/UNICAMP), Campinas, SP, Brasil. 
Em tempos em que se debate a questão instaurada nos anos 1980 pelo nova-iorquino Neil Postman acerca do desaparecimento da infância, a psicanálise recoloca a questão sobre a infância e o infantil em termos de investimentos libidinais, tanto por parte de uma criança quanto por parte de um adulto, isto é, isso que se relaciona com a diferença entre gerações e a diferença entre uma criança e um adulto, portanto, trata-se de diferentes posições libidinais do sujeito em relação à sexualidade que o constitui, e que não é da ordem natural ou biológica. Desloca-se, assim, a questão do declínio, como declínio da imago paternal, para reconhecer nas diferentes experiências cotidianas da criança e do adulto um interrogante: a sexualidade infantil. Isso não supõe que a posição ocupada pela criança nos discursos contemporâneos seja a mesma, mas implica também "a representação que o adulto se faz da infância” (M. Mannoni, 1971, p. 9), como se pretende apresentar a seguir.

A despeito do saudosismo de outros tempos, como confessam alguns, em que a criança é preservada na imagem de um ser ingênuo e inocente, ou, na figura de um ser imperfeito e incompleto, que precisa ser moralizado e disciplinado, restringindo-se ao problema de "natureza humana" e de sua corrupção, consolidou-se no imaginário social uma noção universal e generalizada acerca das crianças, em que a criança é idolatrada e elevada à perfeição, isto é, enquanto o avesso de um sonho não realizado pelos adultos. Tal momento é correlato à dominância do discurso científico, em que a criança constitui-se no plano mítico-imaginário, moldada a partir de categorias fictícias, socialmente fora de contexto, do tempo e da história. Isso não é sem importância, pois revela que os pequenos passaram a ocupar um lugar sutilmente mais perigoso, um lugar de risco, na medida em que, desse lugar e, particularmente, no fantasma dos pais, dos educadores e da sociedade, a criança deve responder a uma demanda impossível e materializar-se nesse ideal. Em risco porque nesse lugar em que ela é convocada a realizar um ideal - o gozo de toda sociedade opera-se a denegação da falta - Verleugnung -, consequentemente, uma negação da diferença sexual e da condição de desejo, condição esta que organiza a própria subjetividade da criança. Como lembra Melman (2010), ao querer criar uma criança modelo, a educação mostra seu voto de morte.

A criança ideal de hoje recorta o fantasma de nossa época, como uma janela que recorta para o sujeito uma paragem imaginária. Nessa lógica, a criança de carne e osso deixa de ser visível, pois o 
que se procura nela, no dia a dia dos adultos com as crianças, são os traços que mantêm consistência à fantasia científica e do mercado, em uma época que não se espera pouco de uma criança. De modo inconsciente, entrega-se ao funcionamento psíquico em termos de garantir o maior grau de satisfação e gozo. Se isso funciona assim, a criança torna-se depositária de todas as angústias e esperanças de um adulto, enquanto objeto de satisfação narcísica, por um lado, e, de outro, como objeto fetiche, que funciona para tamponar a falta no real, ou seja, de recusar os diversos níveis de desmentido que a realidade nos impõe.

A demanda oriunda do "cenário" ou imaginário social de uma época, com sua solda simbólico-imagética e sustentada pelas fantasias, coloca em questão como uma sociedade sonha sua infância e, no nosso caso específico, pontua o lugar que um adulto assume em relação a uma criança, posição que recorta traços imaginários e simbólicos do próprio adulto e do "fantasma" de uma época: "sementinha do mal", "adulto em miniatura", "idade de ouro", "selvagem", "sujeito de direitos” etc., que são diferentes figuras, produções imaginárias e simbólicas para falar da mesma questão, a saber, como e o que os seres humanos produzem simbolicamente em torno do real infantil sexual e inconsciente. Nesse caso, podemos questionar como nossa sociedade vela imaginariamente o sonho da modernidade e até mesmo questionar se a modernidade atual ainda sonha com essa infância. Tal questão, lançada preliminarmente por Lajonquière em seu trabalho acerca das "ilusões psicopedagógicas" em 1999 e retomada no livro Figuras do infantil (2010), tem sido problematizada por vários intelectuais no país e no exterior, ofertando-nos elementos para pensarmos sobre o lugar que a infância ocupa no imaginário social, as relações intergeracionais, as diferentes conjunturas familiares, a (des) implicação e (ir)responsabilidade dos mais velhos em relação à educação do mais novos, o impossível do educar como entendia Freud, entre outros elementos passíveis de articulação.

Ao distinguir o infantil de a criança, a psicanálise rompeu com a tradicional cultura pueril pautada na inocência universal dos pequenos e introduziu as dimensões da singularidade e do desejo - sexual infantil e inconsciente, destacando a intrínseca relação entre a sexualidade e a linguagem na constituição subjetiva dos seres humanos. Com Freud, o infantil deixou de ser adjetivo, distinguindo-se das noções tradicionais e biológicas acerca da criança e da infância. Após a publicação de "Além do princípio do prazer", Freud (1920/1996a) precisou algo de real no infantil, sua dimensão articulada com a pulsão de morte, enquanto fonte de angústia e de trauma, signo de "terror e gozo". O retorno de Lacan ao infantil freudiano trouxe um lugar conceitual ao infantil, articulando-o estruturalmente 
ao processo de constituição subjetiva (Birman, 1997). O infantil do sujeito remete-nos às marcas significantes e às contingências da infância, das vicissitudes do desejo presente em todo ato educativo, seja na família ou na educação regular, vicissitudes essas que são atravessadas pelas fantasias infantis dos adultos, pela presença do inconsciente, pela criança imaginária e consubstanciada no narcisismo primário dos pais e adultos.

Nessa perspectiva, este texto faz uma leitura alinhada aos trabalhos que abordam o mal-estar na educação ao questionar os discursos científicos a partir da noção universal A-criança (Lajonquière, 2010; Voltolini, 2008). Como produção discursiva da atualidade, A-criança se nutre da acentuada produção em torno da infantilização de uma cultura, consumindo o que há de infância e infantil, portanto, o que há de diferença e desejo entre as gerações. Como contraponto, destacam-se a importância da linguagem e da sexualidade na constituição do sujeito infantil, enquanto ponto de ruptura em relação à crença contemporânea que concebe à criança e à infância status de naturez̧a divina, passível até de ser sacrificada no altar dos lares e instituições, e, como aponta a psicanálise, sistematicamente sacrificada no nível simbólico do discurso das ciências e das práticas sustentadas por especialistas que se encarregam delas. Desse modo, ao pensar a passagem de A-criança ao real infantil, como proposto no título deste trabalho, enfatiza-se o deslizamento da questão imaginária, operação que busca enfatizar a constituição do sujeito infantil e das condições para emergência do sujeito do desejo, passagem ao impossível de todo gozar, como dimensão faltosa que impulsiona a constituição subjetiva.

\section{Psicanálise, criança e linguagem}

O campo da psicanálise é coextensivo ao campo da palavra, ou seja, ele está relacionado aos fenômenos de linguagem. A criança vem ao mundo privado da palavra, como revela a etimologia da palavra infans. Sabemos que o recém-nascido chega ao mundo desprovido de completude. A condição biológica é condição necessária, mas não suficiente para que o sujeito se inscreva como um ser que pensa, que sonha, que deseja e que fala, em suma, um ser de linguagem capaz de estabelecer laços sociais. A aquisição da linguagem não se refere 
à necessidade da criança, mas está relacionada a isso que ultrapassa sua condição biológica, isto é, a demanda e o desejo do Outro. Ao não se referenciar pela necessidade, mas pelo desejo, o inconsciente subverte a natureza orgânica. Assim, podemos dizer que psicanálise desnaturaliza os discursos sobre a linguagem, sobre a sexualidade e sobre a própria criança.

Em "Função e campo da fala e da linguagem em psicanálise" (1998a), Lacan enfatiza a fala como função e a linguagem como campo, para delimitar a especificidade da psicanálise, que se diferencia da linguagem pensada pelos linguistas, na dimensão descritiva, como em Saussure, que determina a langue (linguagem) e parole (fala). Para a psicanálise, a criança pequena necessita percorrer um caminho lógico no campo da linguagem para exercer a função de sujeito, ser que fala. Assim, pensar a criança e o infantil é pensar o tempo de estruturação do sujeito, que não é o tempo cronológico, como querem os evolucionistas do desenvolvimento e os neurocientistas, mas é um tempo lógico: percurso marcado por momentos lógicos de estruturação psíquica, tais como o estádio do espelho, o complexo de Édipo e de castração. Dito de outro modo, não é possível falar de desenvolvimento na psicanálise, somente é possível falar sobre isso: a estruturação psíquica que se constitui como infantil do sujeito. A ideia de não haver desenvolvimento na psicanálise não implica que o sujeito não venha ocupar diferentes posições na estrutura que o sobredetermina, como nos informam as clínicas da neurose, da psicose, do autismo, da criança.

Robert Lévy (2008) esclarece que há outras leituras, característica das correntes de inspiração evolucionista cujos fenômenos de crescimento e de desenvolvimento da criança foram descritos por etapas e a cada idade pressupõe um conjunto de aspectos que caracterizam o denominado desenvolvimento "normal" da criança, seu nível de maturidade, atraso ou déficit. Tal corrente evolucionista foi inspirada em certas leituras proveniente das análises de Freud sobre a psicogênese das pulsões e das estruturas cognitivas descritas por Piaget. Como sabemos, os ideais psicopedagógicos que sustentam os

118 Estilos clin., São Paulo, v. 21, n. 1, jan./abr. 2016, 114-132. 
dispositivos educacionais modernos são credores dessa noção natural de desenvolvimento, conforme analisado por Lajonquière (1999).

Como explica Lévy (2011), o conceito de maturação, dominante nos trabalhos da década de 1960, foi considerado "bastante impróprio" (p.23), "pouco satisfatório e repleto de equívocos" (p.23), mesmo quando fundamentados no modelo científico de maturação do sistema nervoso. $\mathrm{O}$ autor argumenta que, para a psicanálise, o termo maturação não pode assumir o mesmo significado que possui para o biólogo e para o psicólogo. Em outras palavras, a história libidinal e pulsional, bem como as estruturas inconscientes e o pensamento do ser humano, não estão associadas ao desenvolvimento fisiológico de um órgão, muito menos associados à aparição de um comportamento determinado geneticamente, conforme gostariam que assim o fosse os defensores das tendências evolucionistas e desenvolvimentistas.

É interessante destacar uma pequena observação que Freud faz no prefácio à quarta edição dos "Três ensaios sobre a teoria da sexualidade" (Freud, 1905/1996b, p. 126), em que ele simplesmente diz: se os homens soubessem "aprender através da observação direta das crianças, estes três ensaios poderiam não ter sido escritos". Por um lado, Freud informa-nos que a observação direita é fonte de equívocos, e isso não é pouco. Por outro, lembra-nos que há um saber que demanda elaboração, isto é, a sua construção demanda um tempo que não é o imediato e/ou cronológico, mas um tempo em que, semelhante à estruturação psíquica, caracteriza-se por um tempo lógico decorrente da nossa estrutura de linguagem.

A partir da descoberta do infantil sexual e inconsciente, Freud inscreveu o infantil no campo pulsional e libidinal - infantil que, por sua vez, constitui-se no ato mesmo de recalque psíquico -, "matéria prima" do inconsciente. No texto "Notas sobre um caso de neurose obsessiva”, Freud (1909/1996c) diz: “o inconsciente, expliquei, era o infantil; era aquela parte do eu (self) que ficara apartada dele na infância, que não participara dos estádios posteriores ... e que, em consequência, se 
tornara reprimida" (p. 181). Freud revelou que a sexualidade não é simples, isto é, não há correlação direta entre a sexualidade e o ato sexual, e isso nos faz pensar. A sexualidade barra a simplicidade, pois ela implica a complexidade, na medida em que há duas forças paradoxais em conflito. O que Freud nos informa é que o sintoma emerge do conflito entre uma libido e uma "desautorização" da sexualidade, por meio do recalque. Assim, não é possível falar de sexualidade sem falar de conflito. O paradoxal de tal descoberta é que a significação da sexualidade - infantil e inconsciente - é sua própria negatividade, sua impossibilidade, isto é, o exercício da sexualidade humana só é possível pelo recalque - quando se recalca é porque não se quer nada saber sobre algo que exige ser reconhecido. Como interpela Masotta (1987, p. 38): “O que há no sexo que o sexual deva ser reprimido?". Ele responde "é a própria estrutura da pulsão que não conduz a um Saber desse objeto". O que exige ser reconhecido é que não há saber unido ao objeto, ou seja, não há uma relação harmoniosa entre a sexualidade e o ato sexual; não há uma adaptação entre o objeto e o saber sobre o sentido da sexualidade. É justamente por não haver uma relação estável com o objeto que a sexualidade possui uma relação íntima com a linguagem, na operação lógica constitutiva da subjetividade que se organizará em torno da falta e do significante, isto é, a partir desse furo no gozo do corpo pelo qual o significante é responsável.

A resistência e a aversão com que os homens de ciência da época de Freud receberam os "Três ensaios sobre a teoria da sexualidade" (1905/1996b) revelam a importância e a força de sua descoberta, o que acabou por produzir uma profunda ruptura com o conhecimento positivo. Como explica Masotta (1987), primeiro porque operou um corte com a noção biológica de instinto, na medida em que a pulsão não tem objeto; segundo, rompeu-se com a ideia de uma psicogênese sexual natural, isto é, não há um desenvolvimento natural da sexualidade; e, por último, operou-se um corte com a noção de criança pura e inocente, colocando em xeque a visão tradicional dos sexólogos, para os quais a sexualidade se inicia na puberdade.

Ao associar o infantil a uma forma de gozo e ao inconsciente - já que para a psicanálise a criança é um "perverso polimorfo" e a sexualidade do adulto é sempre infantil -, rompe-se com a ideia evolucionista de infância como fase de desenvolvimento psicológico, que está submetida à genética e/ou à maturação do ser humano, na medida em que o inconsciente não permite evolução nem mesmo 
superação, ou seja, o infantil freudiano se faz na "vertente estrutural da divisão entre o significante e o real do gozo" (Cirino, 2001, p. 16). Nessa perspectiva, o infantil pode ser tomado como parte da estrutura psíquica e libidinal, isto é, o infantil diz respeito ao modo específico em que se estrutura a sexualidade no humano. Jerusalinsky (2011) propõe a diferenciação entre sujeito infantil e o infantil do sujeito para marcar a temporalidade lógica da diferença entre o que é da ordem da sexualidade de uma criança pequena e o que é da ordem do adulto. Segundo o psicanalista, o infantil do sujeito

não corresponde a um tempo cronológico determinado, no sentido de que, de um modo recalcado, constitui aquilo que Freud nomeava como o umbigo do sonho e Lacan denominou fantasma fundamental, que é o que da experiência infantil persiste como marca no sujeito, ou seja, como matriz pelo resto da vida, por toda sua vida. (Jerusalinsky, 2011, p. 33, itálico do autor)

De outro modo, o sujeito infantil corresponde a "esse tempo no qual o sujeito está em vias de constituir-se e portanto, toda a estrutura nele é provisória, ou seja, não definida" (p. 33). Essa noção de "não definição" é fundamental quando se trata de uma criança pequena, isto é, de sua posição enquanto sujeito do inconsciente, o que marca uma diferença radical em relação aos estudos desenvolvimentistas e das neurociências, bem como quanto às questões de manejo no que diz respeito às questões do tratar e do educar uma criança, principalmente, por se tratar de operações lógicas de pensamento e linguagem das quais dependem irremediavelmente a constituição subjetiva da criança, e menos de estimular e/ou condicionar as crianças a automatismos, como propõem as tradicionais teorias cognitivas e comportamentais, ou mesmo a chamada "pedagogia dos sentidos", como tem sido denominado um tipo de pedagogia calcada no conhecimento das neurociências. Como ilustração, vejamos qual é a visão da neurociência quando se trata de aplicá-la à educação: 
A neurociência investiga o processo de como o cérebro aprende e lembra desde o nível molecular e celular até as áreas corticais. A formação de padróes de atividade neural considera-se que corresponda a determinados estados e representaçóes mentais. Como assinala a neurocientista Suzana Herculano-Houzel, o processo de aprendizado e o de lembrança ocorre no cérebro. Quando sabemos como o cérebro funciona, podemos aplicar métodos que otimizam o processo de apreensão de conhecimentos. (Santos, 2010, p. 62)

Depreende-se que, a partir da neurociência, a pedagogia supõe que a aprendizagem e a educação estão relacionadas a certas partes do cérebro, cabendo ao educador estimular os cinco sentidos das crianças pequenas enquanto estratégia para o desenvolvimento de áreas corticais relativas à aprendizagem. Aqui, o princípio epistemológico dominante no positivismo e nos estudos ditos naturais fornece a matriz para as principais teorias pedagógicas contemporâneas, em que predomina a crença de que o objeto é a fonte da verdade, e não o contrário, em que o conhecimento lógico deriva do pensamento e da linguagem.

Há uma pequena passagem no texto freudiano conhecido como a análise do pequeno Hans, em que Freud (1909/1996d). faz observar que o desejo do adulto é "formar uma criança modelo" e, se possível, longe de toda e qualquer fonte de dificuldades, alertando-nos que "prestamos pouca atenção a se tal curso é também para o bem da criança" (p. 128). Tal observação nos mostra a preocupação do psicanalista quanto aos possíveis efeitos do inconsciente do adulto no trato e na educação dos mais novos. Passado mais de um século, a advertência de Freud é mais do que pertinente para nossa realidade educacional, principalmente, quando testemunhamos certa compulsão daqueles que cuidam e educam os mais novos de querer controlar, estimular e modelar as crianças de acordo com a pedagogia em voga, como se fosse possível um caminho mais fácil e seguro para aplacar as incertezas e dúvidas de um adulto em relação à criação e educação de uma criança.

De modo distinto, a psicanálise ajuda-nos a pensar na relação imprescindível que o adulto e a palavra ocupam na constituição psíquica da criança, isto é, em relação à posição simbólica que a criança ocupa no desejo do adulto, pois a criança responde da posição que ocupa no discurso do Outro. O que está certo é que, para a constituição psíquica da criança, esta deve se deparar com o desejo do outro e ceder de seu gozo imaginário a partir da inscrição do significante. No percurso de constituição subjetiva, conforme apontou Lacan (1998b), a “causação do sujeito" decorre de duas operações psíquicas, a alienação e a separação, ambas referidas à relação do sujeito ao Outro. Desse modo, a criança nasce, primeiramente, vinculada ao desejo dos pais, para depois emergir, por meio de operações lógicas, como sujeito no mundo da 
linguagem, como ser que passa a sustentar um lugar no discurso, a partir do lugar de falta que comporta a relação com o Outro.

É importante considerar que o sujeito não é causa de si, já que está alienado à função significante do Outro, que retorna como sujeito dividido. Ao propor o ternário real, simbólico e imaginário (RSI) - enquanto registros psíquicos nos quais se desenvolve toda experiência humana -, Lacan articula a tópica simbólica ao grande Outro, como as regras de linguagem que submetem os seres falantes, isto é, como lugar do significante e da função paterna. O registro imaginário se definiu como o lugar do Eu, como lugar das ilusões, da captação especular e fusão com o corpo da mãe. Já o real foi inscrito por sua negatividade, ou seja, como um resto impossível de simbolizar. Nessa operação primordial, o objeto a é responsável por operar um corte no grande Outro, como parte que se destaca e recorta para o sujeito a falta no Outro, isto é, como marca da impossibilidade do sujeito de restituir a completude do objeto perdido e do encontro do sujeito com o desejo do Outro. O objetpetit a (objeto a) é um termo inventado por Lacan para enfatizar a determinação inconsciente do objeto, marca radical da diferença em relação à noção de objeto da ciência, e designar o "objeto desejado pelo sujeito e que se furta a ele a ponto de não ser representável, ou de se tornar um 'resto' não simbolizável" (Roudinesco \& Plon, 1998, p. 551). Portanto, o objeto pequeno a é uma espécie de matriz inconsciente que produz os objetos nos quais o desejo se alienará. Por ser a marca da falta, o objeto a precipita a emergência do sujeito, enquanto 
uma diferença irredutível, marcado desde então pelo desejo de saber sobre esse impossível objeto não simbolizável, como esse saber é impossível, algo sempre resta, como resto de gozo que carece ser metaforizado pelo sujeito. Assim, as duas operações, alienação e separação, ao mesmo tempo em que cifram o impossível do desejo, o objeto a precipita à operação de cissura e separação em relação ao grande Outro, na medida em que carece de sentido e completude. No entanto, tal passagem não está garantida de modo natural, como gostariam os evolucionistas, nem mesmo seria resultado de uma maior estimulação precoce, como pregam os neurocientistas na educação. Se o adulto toma uma criança para sustentar o saber de uma teoria, algo nesse processo não se articula, a palavra do educador se torna anônima e, muitas vezes, precipita a criança num beco sem saída, isto é, incapaz de desejar desse lugar.

Em outro sentido, podemos dizer que o que legitima o adulto a endereçar a palavra à criança é sua implicação subjetiva junto aos mais novos, implicação que testemunha sua própria história, como sujeito à linguagem e ao desejo e, portanto, sujeito à castração. Ao dar testemunho da realidade impossível e irredutível do desejo, de um desejo não todo, de um falta-a-ser da sexualidade humana, o adulto acena para outra possibilidade aos mais novos, com a perspectiva futura de poder conquistar um lugar nesse mundo. Mas isso dependerá da forma como o adulto endereça a palavra a uma criança, essa palavra carregada de desejo, possibilitando que a experiência se organize, justamente por receber do adulto "marcas simbólicas", algo de uma transmissão da ordem do desejo de um adulto que assinala um lugar numa história e revela outras possibilidades às crianças, para encontrar seu próprio estilo, ou pelo menos viver sua própria história de modo singular.

De outro modo, dizer do real do infantil implica o impossível da sexualidade, isto é, que é sempre traumática, pois impossível de toda satisfação, fonte de angústia e prazer, ao mesmo tempo em que tal falta abre outras possibilidades. Contudo, tal condição traumatizante da sexualidade é a via civilizatória e humanizante para todo ser novo que chega ao mundo, cota de mal-estar na cultura que cada um tem que se haver por meio do tributo simbólico pago à dívida de filiação, como prova da transmissão de um desejo, mas de um desejo advertido, não todo.

Concordamos com Lajonquière (2010, pp. 62-63), para quem “educar é transmitir marcas simbólicas que possibilitem à criança 
conquistar para si um lugar numa história, mais ou menos familiar, e, dessa forma, poder se lançar às empresas do desejo". Os caminhos da educação, como diz o título de um clássico trabalho de Françoise Dolto (1998), ilustra bem essa questão, ou seja, há um percurso, um processo metafórico que cada um deverá percorrer e fazer algo com esse resto de gozo que demanda um novo sentido, na perspectiva de vir-a-ser no mundo da palavra. Caso diferente seria produzir um modelo, com direito à marca e grife - grifes da nosografia contemporânea dos "distúrbios" do não aprender, por exemplo. Nesse ponto, podemos enfatizar que a psicanálise, no campo da investigação, da clínica e do saber, aponta para elementos estruturais que estão em jogo no processo de educar uma criança.

\section{Psicanálise e educação}

No momento em que a sociedade vive seu ápice de controle matematizado da realidade, de excesso de conhecimento e informações, em que as incertezas são insuportáveis, as experiências acumuladas de uma tradição e a esperança são substituídas por verdades científicas, cálculos estatísticos e projeções, em que as tecnologias reconstroem os limites do humano em direção ao infinito e as coordenadas simbólicas cedem espaço ao espelho imaginário dos objeto-gadgets, que vinculam a mensagem de um falta a gozar mais (rendimento, imediatismo, consumismo, individualismo), constata-se que, quando o que está em jogo é cuidar e educar os mais novos, os adultos ou entram na "onda" de tudo gozar ou se tornam vítimas queixosas.

O campo de estudo em Psicanálise e Educação tem questionado os efeitos de tais transformações históricas sobre a relação dos adultos em relação às crianças nesses tempos ditos hipermodernos. Poder-se-á dizer que vivemos sob o efeito de certo estranhamento relacionado à própria institucionalização da infância, como efeito iatrogênico, na medida em que os jovens retornam aos adultos alguma coisa que receberam deles, seja em termos de distanciamento e falta de reconhecimento ou mesmo de uma impossibilidade de habitar um mundo em comum. Enquanto os mais novos nada querem saber dos mais velhos, estes reclamam dos primeiros uma total falta de civilidade, responsabilidade e desejo em relação às coisas do mundo e aos mais velhos. No que se refere à vida cotidiana com as crianças, 
podemos observar os dois lados dessa questão, isto é, tanto sobre a forma como os novos se posicionam em relação ao desejo do Outro, seja por meio do laço social da família, das instituições sociais, da escola, da mídia espetáculo etc., quanto o seu avesso, ou seja, como os "adultos" se posicionam no laço social com os mais novos. Essa questão se coloca irredutível quando nos interrogamos acerca disso que faz laço social entre esses dois mundos, a saber, a palavra de um adulto a uma criança.

Em "O mal-estar na civilização", Freud (1929/1996e) afirma que "a educação se comporta como se equipasse pessoas de uma expedição polar com trajes de verão e mapas dos lagos italianos” (p. 137). O psicanalista de Viena criticava a educação religiosa de sua época por não preparar as crianças para a realidade do desejo, na medida em que deixa os mais novos sem referências para lidar com a sexualidade, característica do infantil, e a própria agressividade que o mundo lhes reserva. Em suma, Freud aponta para algo que é desproporcional em relação ao que é demandado pelo adulto, quando de um desconhecimento sistemático em relação ao desejo. Digamos, por ora, que tal expedição polar só poderia terminar tragicamente, obviamente.

Com o passar dos tempos, sabemos que os obstáculos colocados às crianças são outros, mas não menos perigosos, obstáculos à subjetividade e à transmissão, que vão desde as ilusões impostas pelo atual reducionismo imposto pela escolarização, que promete uma educação ideal que mal reconhece a especificidade do sujeito infantil, passando por uma sociedade saturada de (des)informações sobre os pequenos até o assédio feroz do poder das grandes corporações financeiras e comerciais que, como "mestres" deste milênio, ditam os padrões culturais e de consumo voltados à infância.

$\mathrm{Na}$ linha argumentativa deste artigo, entende-se que esse estranhamento entre mundos revela, por um lado, o interesse obsessivo de querer saber cada vez mais como a criança "funciona", visando eliminar todas as incertezas e aumentar o controle, e, por outro, a "miséria simbólica" de nossos tempos, que corresponde também ao empobrecimento da relação dos adultos com os mais novos. $\mathrm{O}$ paradoxal é que esse obsessivo querer saber mais sobre a criança revela-se um saber viver menos com ela, o que nos coloca novas perguntas e novos enigmas sobre o mal-estar no mundo contemporâneo. Desse modo, e paradoxalmente, o sentimento de estranhamento do adulto em relação à criança vem acompanhado por certos excessos, mas que 
se revelam um saber de menos quando relacionados ao cuidado e ao governo dos mais novos. Há algo da dimensão do desamparado e da invenção, enquanto marcas de nossa modernidade, que insiste em não ser reconhecido.

Se, por um lado, celebramos o sentimento de infância inaugurado com a modernidade, como nos faz pensar Ariès (1981, p. 277), em que "a família e a escola retiraram juntas a criança da sociedade dos adultos", visando à educação das crianças e submetendo-a "a uma espécie de quarentena antes de deixá-la unir-se aos adultos"; por outro, trata-se, ainda, do dever e da implicação de um adulto com a árdua tarefa de acompanhar uma criança para uma vida em comum. No nosso entender, o que torna tal questão paradoxal, e, portanto, nos apresenta como uma dimensão para reflexão, é que será justamente em torno das relações intergeracionais, isto é, em torno da transmissão e do laço social adulto-criança que se "escuta" certo estranhamento e inquietude com relação à educação dos mais novos.

Para a psicanálise, tal questão está mais associada à criança imaginária do que à criança real e concreta, isto é, está situado em relação ao fantasma imaginário dos pais, dos professores, de uma sociedade, em torno do empuxo imaginário que desperta uma criança ao adulto, em que o retorno infantil do sujeito se apresenta em sua dimensão real. A questão é saber como nós, adultos, nos posicionamos em termos de disponibilidade para escutar e acolher isso que é da ordem desse retorno. Nesse ponto, devemos colocar a pergunta: hoje, qual é a mensagem que a criança recebe do Outro social, de seus pais e educadores? Para dizer com Freud, qual é a moral sexual "civilizada" de nossa cultura? Poderíamos dizer com tranquilidade que nossas crianças se encontram em melhor posição do que aquelas da historieta da expedição polar?

Ao que parece, na sociedade hipermoderna, ninguém está disposto a gozar menos. Dito de outro modo, os adultos esperam que a criança venha realizar todas as fantasias que quando crianças não puderam realizar, por um lado, enquanto, por outro, vive-se sob o lema cultural em que se espera da criança que ela realize um impossível, marca da "revivescência e reprodução do próprio narcisismo" do adulto em relação à criança. Lembremo-nos do ensaio "Sobre o narcisismo" (1914/1996f), em que Freud faz referência indireta ao título de um quadro de Arthur Drummond, "His majesty the baby", para se referir ao lugar central que a criança ocupa no sistema narcísico, revelando que a atitude dos pais para com os filhos é de 
uma "revivescência e reprodução de seu próprio narcisismo, que há muito abandonaram" (p. 97). Essa tendência de querermos renovar todas as reinvindicações por satisfação às quais fomos forçados a renunciar, suspendendo todas as dificuldades e limites que a vida e a sociedade impõem,

A doença, a morte, a renúncia ao prazer, restriçôes à sua vontade própria não a atingirão; as leis da natureza e da sociedade serão ab-rogadas em seu favor; ela será mais uma vez realmente o centro e o âmago da criação - "Sua Majestade o Bebê”, como outrora nós mesmos nos imaginávamos. A criança concretizará os sonhos dourados que os pais jamais realizaram. (Freud, 1914/1996f, p. 98)

Tal atitude encontra-se sob a compulsão de atribuir todas as perfeições às crianças e de ocultar todas as deficiências delas, o que também implica o repúdio de toda e qualquer alteridade introduzida quando se trata de novas crianças no seio da família e da sociedade. A mensagem que uma criança recebe de nossa sociedade contemporânea está mais vinculada ao gozo pleno de todas as satisfações do que à ética do "cuidado de si", ou à ética do desejo, como articula-se na psicanálise.

Como Freud constatou em relação à constituição do infantil, há um sentimento de repúdio ou recusa em aceitar o "desmentido que a realidade nos impõe" acerca de uma crença que possuímos, conservando-se essa crença ao mesmo tempo em que a abandonamos, na medida em que o desmentido se apaga da lembrança $(\mathrm{O}$. Mannoni, 1973, p.11). Essa posição do sujeito somente é possível devido à clivagem do psiquismo, de uma posição dividida, em que opera a conservação da crença no nível dos processos primários. Desse lugar, assistimos a compulsão de atribuir à criança todas as perfeições; cria-se a ilusão da existência da criança perfeita, universal, em suma, a criança dos sonhos.

\section{Imaginário social: A-criança}

Como apresentado anteriormente, longe de negarmos as implicações históricas, políticas e culturais que atravessam a constituição da infância, a psicanálise ajuda-nos a pensar os discursos naturalizados em torno da criança, na medida em que nos possibilita conhecer a posição que essa ocupa no laço social proposto pelos artifícios sociais 
modernos, bem como a posição que o adulto assume na relação que estabelece com os mais novos. Nesse ponto, devemos retomar um movimento próprio à psicanálise que consiste em interrogar os discursos que embalam a produção mítica de uma criança ideal, criança tributária dos discursos científicos acerca da realidade do objeto. Tal leitura, praticamente consensual entre vários autores da psicanálise no campo da educação, remete-nos ao termo "A-Criança" empregado, inicialmente, por Voltolini (2008) para designar a criança "nascida da confluência dos vários discursos científicos que a tomam como objeto para descrever-lhe e fundar práticas em torno das crianças" (Resumo, para.1) e, posteriormente, desenvolvido por Lajonquière (2010), em Figuras do infantil, que nos fornece certa referência para pensarmos as fantasias que sustentam a ilusão em torno da infância na contemporaneidade. Segundo o autor,

a naturalização violenta da infância, via império do tecnocientificismo médico-psico-pedagógico pão-nosso da vida cotidiana, nas últimas décadas, deu lugar a um fantasma singular que ultrapassa toda divisão societária: A-criança. Esse ser natural, dotado de direitos e necessidades educativas mais ou menos especiais, porém sempre clamante de satisfação, virou parâmetro comportamental onipresente em nossa vida cotidiana com as crianças. (Lajonquière, 2010, p. 19)

Ao contrário dos que advogam o fim da infância, a noção A-Criança revela certa "hipertrofia" da infância no imaginário social, num contexto marcado pelo excesso, de produção de objetos, direitos à criança e atenção de especialistas, sejam médicos, pedagogos, psicólogos etc. Nesse sentido, explica o psicanalista, A-Criança tem ameaçado o próprio tempo da infância, que outrora era o abrigo das crianças, o "tempo de espera" - não no sentido maturacional, mas cultural - do tempo anterior à entrada no mundo dos adultos, um tempo de encontro com a demanda do Outro, de constituição psíquica e de metaforização e enunciação do sujeito, como dimensão trifásica da infância. 
A ilusão expressa no ideal A-Criança possui consistência de uma crença, isto é, num desejo recalcado, que retorna como desejo de uma infância sem limites, o que implica pensar no próprio apagamento das diferenças sexuais e das diferenças entre as gerações, uma espécie de curto-circuito que impossibilita ao adulto endereçar-se à criança real. Sabemos que o apagamento da dissimetria entre as gerações é o equivalente ao apagamento da castração. Paradoxalmente, o que interessa às crianças é a castração, isso que é da ordem do desejo do adulto, mesmo quando este se furta dessa posição, o que nos solicita não subestimar a demanda de uma criança, qual o lugar que o adulto assume no desejo de uma criança.

No entanto, temos testemunhado pela via do adulto um querer imaginário de se assemelhar e coincidir com o mundo da criança, convocando toda sorte de satisfação possível, atitude reforçada pelos tempos de um hedonismo ilimitado, retrato paradoxal de nossos tempos em que, em nome dos direitos da criança, os mais novos ficam à mercê da própria sorte, tanto de suas pulsões quanto do gozo infantil do Outro. Como vemos, trata-se de questões que colocam o inconsciente a "céu aberto", como diria Lacan. Enfim, como poderia ser diferente, se hoje celebramos a redução do imaginário humano ao seu fantasma científico e encarnado nos objetos de consumo? Seria possível ao adulto cair dessa posição e olhar para o sujeito na criança? Seria impossível sustentar a angústia do infantil para recolocar a infância como espaço de invenção? Essas questões devem manter o interrogante em aberto, e mais ainda: a quem serve o discurso universal A-Criança, já que o sujeito do desejo aí não se encontra?

FROM THE-CHILD TO THE CHILDHOOD REAL: PSYCHOANALYTIC REFLECTIONS ON CHILDHOOD

\footnotetext{
Abstract

Using the conceptual investigations of psychoanalysis in the field of education, this work presents elements to think about childhood in our daily practice with children and adolescents. In this sense, the scientific discourses that produce a universal, timeless, and ideal notion of childhood are questioned, since such idealization involves adults' rejection of their duty of educating the youngsters.
} 
The status of the subject of desire and the possible positions that children take in the face of the demand of adults are emphasized.

Index terms: childhood; infant; education; psychoanalysis.

DESDE EL-NIÑO A LO REAL INFANTIL: REFLEXIONES PSICOANALÍTICAS ACERCA DE LA INFANCIA

\section{RESUMEN}

A partir de la indagación conceptual propia del psicoanálisis en el campo de la educación, este trabajo presenta elementos para que se piense sobre la dimensión extranjera de lo infantil en nuestras prácticas cotidianas con los niños y adolescentes. Para ello, se cuestionan los discursos modernos que producen una noción universal, atemporal e ideal de la infancia, en la medida en que dicha idealización implica el rechazo del adulto en relación a su deber simbólico frente a la formación de los más nuevos. Se destaca el estatuto del sujeto de deseo y las posibles posiciones que el niño asume junto a la demanda del adulto.

Palabras clave: infancia; infantil; educación; psicoanálisis.

\section{REFERÊNCIAS}

Ariès, P. (1981). História social da criança e da família. Rio de Janeiro, RJ: Zahar.

Cirino, O. (2001). Psicanálise e psiquiatria com crianças: desenvolvimento e estrutura. Belo Horizonte, MG: Autêntica.

Birman, J. (1997). Além daquele beijo!?: sobre o infantil e o originário em psicanálise. In E. Santa Roza \& E. S. Reis (Orgs.). Da análise na infância ao infantil na análise (pp. 7-37). Rio de Janeiro, RJ: Contra Capa.

Dolto, F. (1998). Os caminhos da educação. São Paulo, SP: Martins Fontes.

Freud, S. (1996a). Além do princípio do prazer. In S. Freud, Ediçâo standard brasileira das obras psicológicas completas de Sigmund Freud (J. Salomão, trad., Vol. 18, pp. 11-75). Rio Janeiro, RJ: Imago. (Trabalho original publicado em 1920)

Freud, S. (1996b). Três ensaios sobre a teoria da sexualidade. In S. Freud, Edição standard brasileira das obras psicológicas completas de Sigmund Freud (J. Salomão, trad., Vol. 7, pp. 119-217). Rio Janeiro, RJ: Imago. (Trabalho original publicado em 1905)

Freud, S. (1996c). Notas sobre um caso de neurose obsessiva. In S. Freud, Edição standard brasileira das obras psicológicas completas de Sigmund Freud (J. Salomão, trad., Vol. 10, pp. 137-217). Rio Janeiro, RJ: Imago. (Trabalho original publicado em 1909)

Freud, S. (1996d). Análise de uma fobia de um menino de cinco anos. In S. Freud, Ediçâo standard brasileira das obras psicológicas completas de Sigmund Freud (J. Salomão, trad., Vol. 10, pp. 13-133). Rio Janeiro, RJ: Imago. (Trabalho original publicado em 1909)

Freud, S. (1996e). O mal-estar na civilização. In S. Freud, Edição standard brasileira das obras psicológicas completas de Sigmund Freud (J. Salomão, trad., Vol. 21, pp. 67-150). Rio Janeiro, RJ: Imago. (Trabalho original publicado em 1929) 
Freud, S. (1996f). Sobre o narcisismo: uma introdução. In S. Freud, Edição standard brasileira das obras psicológicas completas de Sigmund Freud (J. Salomão, trad., Vol. 14, pp. 77-110). Rio Janeiro, RJ: Imago. (Trabalho original publicado em 1914)

Jerusalinsky, A. (2011). Para compreender a criança: chaves psicanaliticas. São Paulo, SP: Instituto Language.

Lacan, J. (1998a). Função e campo da fala e da linguagem em psicanálise. In J. Lacan, Escritos (V. Ribeiro, trad., pp. 238-324). Rio de Janeiro, RJ: Jorge Zahar.

Lacan, J. (1998b). Posição do inconsciente no Congresso de Bonneval (1960, retomado em 1964). In J. Lacan, Escritos (V. Ribeiro, trad., pp. 843-864). Rio de Janeiro, RJ: Jorge Zahar.

Lajonquière, L. de (1999). Infância e ilusão (psico)pedagógica: escritos de psicanálise e educação. Petrópolis, RJ: Vozes.

Lajonquière, L. de (2010). Figuras do infantil: a psicanálise na vida cotidiana com as crianças. Petrópolis, RJ: Vozes.

Lévy, R. (2008). Lo infantil en psicoanálisis: la construcción del sintoma en el niño. Buenos Aires, Argentina: Letra Viva.

Mannoni, M. (1971). A criança, sua “doença” e os outros. Rio de Janeiro, RJ: Zahar.

Mannoni, O. (1973). Chaves para o imaginário. Petrópolis, RJ: Vozes.

Masotta, O. (1987). O comprovante da falta. Liçōes de introdução à psicanálise. Campinas, SP: Papirus.

Melman, C. (2010). Sobre a educação de crianças. In C. Calligaris et al., Educa-se uma criança? (pp. 31-42). Porto Alegre, RS: Artes e Ofícios.

Roudinesco, E., \& Plon, M. (1998). Dicionário de psicanálise. Rio de Janeiro, RJ: Zahar.

Santos, H. de O. (2010). Naves-mãe e a pedagogia dos sentidos: de Campinas, novos paradigmas para a educaçâo infantil no Brasil. Campinas, SP: Komedi.

Voltolini, R. (2008). A escola e os profissionais d'A criança. In $7{ }^{\circ}$ Colóquio do LEPSI - Formação de Profissionais e a Criança-sujeito, 7, São Paulo, SP. Recuperado de http://www.proceedings.scielo. br/scielo.php?script=sci_arttext\&pid=MSC0000000032008000100012\&lng=en\&nrm=abn

\section{NOTA}

1. Este trabalho faz parte das atividades de estudo de pós-doutoramento e conta com apoio da Fundação de Amparo à Pesquisa do Estado de São Paulo (Processo FAPESP 13/02840-6).

ericpassone@yahoo.com.br

Rua Papa Leão XIII, 10/03

13082-793 - Campinas - SP - Brasil. 